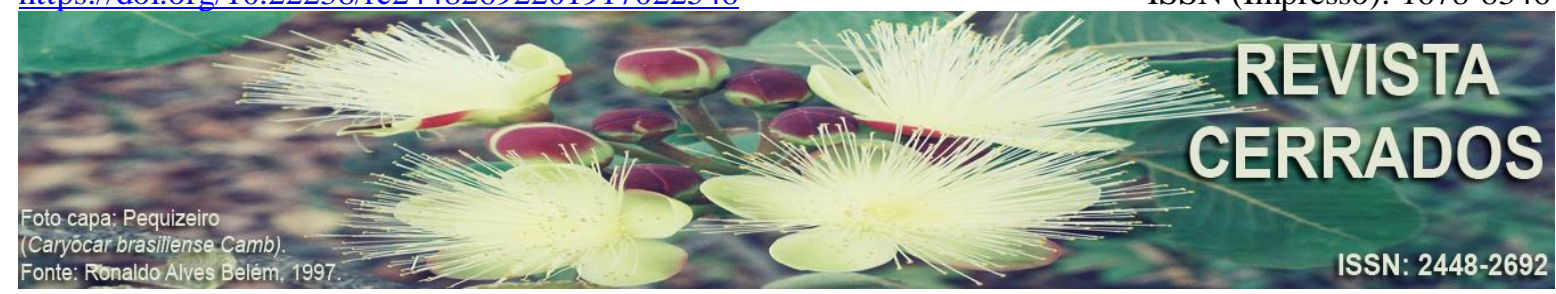

\title{
SEGREGAÇÃO E HANSENIASE: a produção de uma subnormalidade no município de Anápolis (GO)
}

\section{SEGREGATION AND LEPROSY: the production of a subnormality in the county of Anápolis (GO)}

\section{SEGREGACIÓN Y LEPRA: la produción de una subnormalidad en la ciudad de Anápolis (GO)}

\author{
Thalita Aguiar Siqueira \\ Universidade Estadual de Goiás - UEG \\ E-mail: <aguiarthalita29@gmail.com>. \\ Marcelo De Mello \\ Universidade Estadual de Goiás - UEG \\ E-mail: <ueg.marcelo@gmail.com>.
}

\begin{abstract}
RESUMO
O presente artigo apresenta, inicialmente, uma discussão teórica centrada no conceito de segregação residencial. A partir do debate conceitual realizado, foi evidenciada a existência de cenários marcados por complexidades econômicas e sociais em que a segregação residencial é manifestada. Posteriormente, a partir da realização de trabalhos de campo e da aplicação de questionários, foi investigada a segregação residencial em um bairro caracterizado pela precarização na reprodução da vida de cidadãos que habitam um espaço produzido, na primeira metade do século XX, para abrigar portadores da hanseníase. Trata-se do bairro Novo Paraíso, na cidade de Anápolis (GO), que apresenta uma realidade repleta de ações segregadoras.
\end{abstract}

Palavras-chave: Processo Histórico. Segregação. Hanseníase.

\begin{abstract}
The present article presents, in first place, a discution about the concept of residencial segregation. Based on the conceptual debate, was evidenced the existence of scenarios marked by economical and social complexities, in wich the residencial segregation is manifested. After, based on the realization of camp works and in the aplication of questionnaires, was investigated the residencial segregation in a neighborhood characterized by precariousness in the reprodution of the life of citizens that live in a space produced, in the
\end{abstract}


SIQUEIRA, T. A.; MELLO, M.

Segregação e Hanseniase: a produção de uma subnormalidade no município de Anápolis (GO)

first half of the 20th century, to home to leprosy patients. It is the neighborhood Novo Paraíso, in the city of Anápolis, which presents a reality full of segregating actions.

Keywords: Historical Process. Segregation. Leprosy.

\section{RESUMEN}

El presente artículo apresenta, inicialmente, una discusión teórica sobre el concepto de segregación residencial. A partir del debate conceptual realizado, fue evidenciada la existencia de escenarios marcados por complejidades económicas y sociales en que la segregación residencial se manifesta. Enseguida, a partir de la realización de trabajos de campo y de la aplicación de cuestionarios, fue investigada la segregación residencial en un barrio caracterizado por la precarización en la reprodución de la vida de ciudadanos que viven en un espacio producido, en la primera mitad del siglo XX, para albergar a portadores de lepra. Es el barrio Novo Paraíso, en la ciudad de Anápolis, que presenta una realidad repleta de acciones segregadoras.

Palabras-clave: Proceso Histórico. Segregación. Lepra.

\section{INTRODUÇÃO}

A sociedade contemporânea é marcada por uma expressiva diversidade. Esta característica pode ser percebida de diferentes maneiras. Ao analisar a diversidade territorializada no espaço urbano, podemos, por exemplo, destacar a questão da segregação residencial. E foi este fenômeno urbano o elemento privilegiado neste artigo. Para tanto, percorremos um caminho investigativo alicerçado nas complexas relações produtoras dos processos segregadores que repercutem na questão da habitação.

Partimos do princípio que o espaço urbano é marcado por uma valorização diferencial de seu solo (CORREA, 1995). Por esta razão, a renda é uma variável fundamental quando consideramos a questão da habitação, pois a aquisição de uma moradia se dá na dimensão concreta de um mundo marcado por áreas urbanas mais valorizadas e áreas urbanas menos valorizadas.

Neste contexto, em que a habitação é uma mercadoria, a renda é definidora do lugar em que as famílias residem. Da mesma forma, a renda impõe uma diferenciação de padrões construtivos nas habitações: tanto na dimensão unitária de uma casa, como em uma perspectiva do ordenamento territorial em que várias moradias foram construídas em espaços específicos. Neste sentido, é importante destacar a assertiva de Carlos (2007), que ensina que 
SIQUEIRA, T. A.; MELLO, M.

Segregação e Hanseniase: a produção de uma subnormalidade no município de Anápolis (GO)

à medida que os sujeitos sociais, através de suas ações, produzem sua existência, produzem, também, espaço.

Em um mundo urbano marcado por complexidades de distintas matizes, a investigação da realidade deve ser balizada por robustos alicerces conceituais. A presente pesquisa apresenta, em um primeiro momento, uma discussão centrada no conceito de segregação residencial: em um contexto em que a dinâmica urbana materializou contradições sócio-espaciais ${ }^{1}$. A intenção foi produzir condições teóricas para a análise da segregação residencial imposta aos hansenianos pobres e migrantes que aportaram na cidade de AnápolisGO, na primeira metade do século XX; bem como investigar a continuidade das ações segregadoras direcionadas a esta população.

No curso do processo investigativo, a aproximação entre o conceito de segregação residencial e a realidade pesquisada foi pautada na realização de trabalhos de campo e na aplicação de questionários. Estes procedimentos indicaram que a população residente no bairro criado na primeira metade do século XX, para segregar hansenianos, ainda é caracterizada pela baixa renda e pela ausência de serviços e equipamentos públicos fundamentais.

Trata-se do bairro Novo Paraíso, qualificado pelo Instituto Brasileiro de Geografia e Estatística (IBGE, 2010) como área subnormal. O IBGE classifica uma área subnormal como um conjunto constituído por, no mínimo, cinquenta e uma unidades habitacionais, caracterizadas pela ausência de título de propriedade e por, pelo menos, uma das características que seguem: irregularidade das vias de circulação e do tamanho e forma dos lotes e/ ou carência de serviços públicos essenciais, como coleta de lixo, rede de esgoto, rede de água, energia elétrica e iluminação pública. Ainda, segundo o (IBGE,2010), sua existência está relacionada à forte especulação imobiliária e fundiária, ao espraiamento de tecidos urbanos marcados pela carência de infraestruturas e, por fim, à periferização da população.

\section{A segregação: breve histórico}

A partir de avanços técnicos o homem passou a viver em espaços cada vez mais densamente povoados, concentrando atividades econômicas, de lazer, cultura e outras inerentes a vida em sociedade. Os primeiros avanços técnicos foram produzidos em um

\footnotetext{
${ }^{1}$ Para Souza (2015, P.16), o sócio-espacial com hífen qualifica não apenas o "espacial”, mas considera também as relações sociais. Desta forma ao longo deste trabalho utilizaremos a palavra "Sócio-espacial".

Revista Cerrados, Montes Claros/MG, v.17, n. 2, p. 25-46, jul./dez.-2019.
} 
SIQUEIRA, T. A.; MELLO, M.

Segregação e Hanseniase: a produção de uma subnormalidade no município de Anápolis (GO)

mundo agrícola que, a partir da produção de excedentes, foi envolvido por atividades comerciais; bem como pelo surgimento de cidades. Segundo Souza (2010), Jericó foi a primeira cidade com este registro. Ela está localiza as margens do rio Jordão e sua presença é frequente em relatos bíblicos. Naquela época, processos segregadores já se faziam presentes: alguns grupos, como os leprosos ${ }^{2}$, eram obrigados a viver isolados, devido a sua condição física; assim como os cegos, os paralíticos e as viúvas. Para Souza (2010, p.46):

As primeiras cidades surgem como resultado de transformações sociais geraiseconômicas, tecnológicas, políticas e culturais -, quando, para além de povoados de agricultores, que eram pouco mais que acampamentos permanentes de produtores diretos que se tornaram sedentários, surgem assentamentos permanentes maiores e muito mais complexos, que vão abrigar uma ampla população de não produtores: governantes (monarcas, aristocratas) funcionários (como escribas), sacerdotes e guerreiros. A cidade ira também abrigar artesãos especializados, como carpinteiros, ferreiros, ceramistas, joalheiros, tecelões e construtores navais, os quais contribuirão, com suas manufaturas, para o florescimento do comercio entre povos.

Considerando as primeiras cidades, notamos que uma de suas características era a proximidade de cursos d'água, o que por si só já demonstra uma diferenciação espacial. Neste cenário, determinados segmentos sociais, por motivos distintos, eram obrigados a viver em locais específicos. Geralmente, os locais habitados pelos segregados eram marcados pela ausência de amenidades.

Certamente, processos segregadores foram intensificados a partir da Revolução Industrial. Naquele momento, o crescimento das cidades e as diferenças na distribuição de renda alteraram intensamente as paisagens, revelando a segregação residencial em curso. A Revolução Industrial consolidou a cidade como centro da vida burguesa, chamando a atenção tanto pela ampliação de sua dimensão física, quanto de sua complexidade funcional. Nesse sentido, Lefebvre (2001) ressalta que o ponto de partida para entender os problemas urbanos é o processo de industrialização, qualificado como "motor das transformações da sociedade." (LEFEBVRE, 2001, p.11). Souza (2010, p.68) analisa a questão da segregação e esclarece:

A segregação (residencial) induzida pode ser observada em cidades desde a antiguidade. O moderno capitalismo, inicialmente na Europa, depois em outras partes do mundo, irá, todavia, acarretar uma mudança de magnitude (e de escala) no padrão de segregação.

Simultaneamente ao rápido crescimento das cidades, emergem processos de redefinição de sua estrutura. Ao analisar o processo de segregação, percebemos que a

\footnotetext{
${ }^{2}$ Portadores do mal de Hansen.
}

Revista Cerrados, Montes Claros/MG, v.17, n. 2, p. 25-46, jul./dez.-2019. 
SIQUEIRA, T. A.; MELLO, M.

Segregação e Hanseniase: a produção de uma subnormalidade no município de Anápolis (GO)

desigualdade entre segmentos é fator dominante na composição da diferença entre classes sociais. Com relação a este aspecto, Rousseau (1978, p.12) esclarece que:

\begin{abstract}
Na espécie humana existem dois tipos de desigualdade: uma chama de natural ou física, porque é estabelecida pela natureza, e que consiste na diferença das idades, da saúde, das forças do corpo e das qualidades do espírito, ou da alma; a outra, que se pode chamar de desigualdade moral ou política, porque depende de uma espécie de convenção, e que é estabelecida ou, pelo menos, autorizada pelo consentimento dos homens. Consiste esta nos diferentes privilégios de que gozam alguns com prejuízo dos outros, como ser mais ricos, mais honrados, mais poderosos do que os outros, ou mesmo fazerem-se obedecer por eles.
\end{abstract}

Dessa forma, Rousseau (1978) oferece elementos que permitem qualificar o processo segregador como produto de uma conduta moral e ética negativa e egocêntrica, que, por diversas razões, influenciam diretamente a vida das pessoas, tanto nos aspectos matérias, quanto nos simbólicos. O raciocínio desenvolvido pelo filósofo auxilia no entendimento dos estigmas associados ao lugar de moradia, principalmente, quando consideramos os processos de territorialização de distintos segmentos sociais.

Um exemplo marcante de segregação foi a constituição de guetos. Em distintos países os guetos se fizeram presentes: podemos citar os guetos de Veneza, que segregavam os judeus; os das cidades sul-africanas, na época do Apartheid ${ }^{3}$, segregando a população negra; e o caso dos Estados Unidos, onde a questão étnica influencia fortemente o local de moradia, Souza (2010). Em todo o mundo processos segregadores são percebidos. Seja em sociedades marcadas por expressivas conquistas sociais ou em sociedades caracterizadas por precariedades na oferta de serviços e equipamentos públicos. Ao abordar a realidade brasileira, nos defrontamos com distintos cenários em que ações segregadoras se fazem presentes.

No Brasil, cidades grandes, médias e pequenas revelam a presença da segregação. No que se refere às cidades médias, Anápolis-GO revela interessantes traços territorializados de segregação. O presente artigo destacou o surgimento de um bairro, na primeira metade do século XX, a partir da criação de um leprosário: o bairro Novo Paraíso, que ainda hoje é estigmatizado por ter abrigado hansenianos.

Contudo, antes de apresentar a especificidade do bairro Novo Paraíso, é importante destacar que a segregação é promovida por diversos motivos: religiosos, étnicos,

\footnotetext{
${ }^{3}$ Regime de segregação racial adotado de 1948 a 1994 pelos sucessivos governos do Partido Nacional na África do Sul, no qual os direitos da maioria dos habitantes foram cerceados pelo governo formado pela minoria branca. A esse respeito ver Pereira (2010).
}

Revista Cerrados, Montes Claros/MG, v.17, n. 2, p. 25-46, jul./dez.-2019. 
SIQUEIRA, T. A.; MELLO, M.

Segregação e Hanseniase: a produção de uma subnormalidade no município de Anápolis (GO)

sociais, dentre outros. Outro fato que deve ser ressaltado é que a segregação se faz presente desde os tempos mais remotos. Nesta perspectiva, os intrincados contextos investigados, no âmbito das ciências humanas e sociais, possibilitaram um amadurecimento conceitual direcionado para as análises dos processos segregadores. O tópico que segue destaca esta questão.

\section{O Conceito de segregação}

A palavra segregar remete ao significado de separação; ou seja, separar em grupos. Como destacado no tópico anterior, processos segregadores estão presentes na história da humanidade. Todavia, o fato das relações sociais territorializadas serem marcadas pelo aumento de suas complexidades solicita, ininterruptamente, uma atualização conceitual quando se intenta analisar as dinâmicas que se fazem presentes na sociedade.

O amadurecimento de um conceito deve acompanhar as transformações evidenciadas pelo mundo concreto, a partir da sistematização de debates e ações investigativas que contemplem, por exemplo, fenômenos como a segregação, que interessa a diversas áreas do conhecimento.

Considerando as diferentes abordagens relativas à segregação, Clarck (1985) e Vasconcelos; Corrêa; Pintaudi (2013) apresentam o conceito de segregação fundamentado na economia neoclássica, baseados na abordagem do livre-comércio. Geralmente, este conceito é utilizado em pesquisas voltadas para a maximização da renda. De acordo com esta abordagem, "a segregação é [...] o resultado de uma competição pela terra urbana" (VASCONCELOS; CORREAA; PINTAUDI, 2013, p.9).

Por sua vez, uma das abordagens mais destacadas é a vinculada à sociologia urbana, que apresenta como fundamento teórico a ecologia humana. Tais estudos surgem na Escola de Chicago, com Park (1916) e Mackenzie (1925), e se baseiam na questão da luta pelo espaço travada por grupos sociais. Autores como Clarck (1985); Corrêa (1995); Vasconcellos (2013); entre outros, apresentam esta abordagem, que considera a segregação "uma concentração de tipos de população dentro de um dado território." (CORRÊA, 1995, p.59).

Posteriormente, Shevky e Bell (1961 apud CORRÊA, 1995) definiram segregação como "áreas sociais" "marcadas pela tendência a uniformidade da população em termos de Revista Cerrados, Montes Claros/MG, v.17, n. 2, p. 25-46, jul./dez.-2019. 
SIQUEIRA, T. A.; MELLO, M.

Segregação e Hanseniase: a produção de uma subnormalidade no município de Anápolis (GO)

três conjuntos: status socioeconômico, urbanização e etnia"; originando bairros homogêneos segregados (SHEVKY; BELL, 1961 apud CORREAA, 1995).

Outra perspectiva relevante, no estudo da segregação, é a ecologia fatorial ${ }^{4}$. Berry (1971) introduz a análise de padrões sociais e espaciais na cidade, (CLARCK, 1985). De acordo com essa abordagem, a segregação gera padrões e organização interna, o que é visivelmente percebido na paisagem urbana, principalmente em se tratando da relação centroperiferia, onde, geralmente, os bairros visivelmente pobres se localizam as margens da malha urbana.

Segundo Vasconcelos (2004, p.260), "na Geografia, um dos primeiros autores a utilizar o conceito de segregação foi Robert Dickinson, no seu livro de 1947, quando examina esse conceito juntamente com os de invasão e sucessão".

Na geografia brasileira, diversos autores trabalham o conceito de segregação. Para Corrêa (1995, p.61), "a segregação é uma expressão espacial das classes sociais". Outro nome importante no estudo da segregação é o do urbanista Flávio Villaça (2001). Ele destaca que "a segregação é um processo no qual diferentes classes ou camadas sociais tendem a se concentrar cada vez mais em diferentes regiões gerais ou conjuntos de bairros da metrópole." (2001, p.142). Villaça (2001) analisa a organização social vigente. O autor apresenta uma visão ampla das relações sociais, econômicas e culturais. Relações cotidianas que se tornam complexas, à medida que são regidas pela organização espacial das cidades.

Souza (2010) aborda a segregação residencial a partir de um conjunto de problemas. Para o geógrafo, trata-se de um fenômeno urbano que ocorre com mais intensidade nas grandes cidades. O referido autor aponta a segregação residencial como resultado de vários fatores: como a pobreza, o racismo e as diferenciações espaciais em termos de infraestrutura. Desta forma, ele enfatiza que "a segregação deriva de desigualdades e, ao mesmo tempo, retroalimenta desigualdades [...], ao condicionar a perpetuação de preconceitos e a existência de intolerância e conflitos. " (SOUZA, 2010, p.84).

Além de ser produto de relações empreendidas entre o homem e o espaço, o processo segregador acaba gerando novas condições para que a estrutura segregadora seja reproduzida das mais diferenciadas formas, promovendo, inclusive, a violação dos direitos

\footnotetext{
${ }^{4}$ Para Corrêa (2016, p. 15), a análise fatorial produz "uma classificação de cada unidade de área em relação a cada fator. Trata-se do factor score, que indica quantitativamente a importância de cada unidade de área no âmbito de cada fator. Por intermédio da análise de agrupamento é possível agrupar os setores censitários que apresentam as mesmas combinações de fatores obtidos da análise fatorial".
}

Revista Cerrados, Montes Claros/MG, v.17, n. 2, p. 25-46, jul./dez.-2019. 
SIQUEIRA, T. A.; MELLO, M.

Segregação e Hanseniase: a produção de uma subnormalidade no município de Anápolis (GO)

humanos. Segundo SOUZA (2010, p.84), “a segregação residencial é um resultado de vários fatores os quais, em si, são altamente problemáticos: da pobreza ao papel do Estado na criação de disparidades espaciais em matéria de infraestrutura e no favorecimento dos moradores de elite".

A sociedade capitalista se especializou na criação e recriação de processos segregadores, que, por sua vez, estão associados à reprodução ampliada do capital e manutenção do status quo. A ciência, juntamente com a sociedade organizada, deve analisar os complexos processos segregadores, com o intuito de apontar a existência de uma intencionalidade em suas conduções. O tópico abaixo qualifica processos segregadores presentes no espaço urbano.

\section{Os diferentes tipos de segregação}

Villaça (2001, p.142) destaca que "há segregações das mais variadas naturezas". Para o urbanista, preponderam às derivadas dos antagonismos presentes entre as distintas classes sociais, etnias e nacionalidades. A segregação das classes sociais é a que determina a organização das cidades brasileiras. Assim, a segregação é um processo de diferenciação ou separação da sociedade, onde um grupo não se relaciona com outro. A segregação:

Reflete uma diferenciação entre grupos sociais. Em outras palavras: diferenças econômicas, de poder, de status, etc. entre diversos grupos sociais se refletem no espaço, determinando ou pelo menos influenciando decisivamente onde os membros de cada grupo podem viver (SOUZA, 2010, p.67).

Para Souza (2010), além dos tipos de segregação que ocorrem por indução, há outras modalidades promovidas pela classe social situada de maneira destacada no processo de tomada de decisões. Trata-se da auto segregação praticada por segmentos sociais privilegiados, que se distanciam o máximo possível dos problemas presentes da cidade. Souza (2010, p.71) esclarece:

Alguém poderia alegar que, também no caso da auto segregação, tampouco se trata de uma "escolha", pois as pessoas tentam escapar de problemas. Essa seria porém uma interpretação forçada, por duas razoes: primeiramente, por que os que se auto segregam não costumam ver seus antigos espaços com olhos nostálgicos, ou seus novos espaços como representando uma perda. Em segundo lugar por que os que se auto segregam, na condição de moradores, são em grande parte, os mesmos que, na condição de elite dirigente, são ao menos, corresponsáveis pela deterioração das condições de vida na cidade, inclusive no que se refere à segurança pública, seja por Revista Cerrados, Montes Claros/MG, v.17, n. 2, p. 25-46, jul./dez.-2019. 
SIQUEIRA, T. A.; MELLO, M.

Segregação e Hanseniase: a produção de uma subnormalidade no município de Anápolis (GO)

suas ações, seja por sua omissão. Em suma, há de se manter uma distinção muito forte entre a segregação induzida e a auto segregação.

A auto segregação, sem dúvida, é uma segregação que ressalta a desigualdade na distribuição da renda. Nesta perspectiva, Lojkine (1997) apresenta tipos de segregação urbana: uma produzida pela oposição do preço do solo entre o centro e a periferia, outra derivada da separação entre zonas de moradias das classes de alta renda das camadas sociais com renda mais baixa e das zonas especializadas. O primeiro tipo de segregação, apresentado por Lojkine, dá origem ao segundo, pois a diferenciação do preço do solo influencia diretamente no local da moradia, impedindo que a população de baixa renda adquira um imóvel em um bairro marcado pela oferta qualificada de serviços e equipamentos públicos. Na periferia, por questões de falta de amenidades, os imóveis são mais baratos por não ofertarem uma infraestrutura básica. Conforme Corrêa (1995, p.69):

A segregação é dinâmica, envolvendo espaço e tempo, e este processo de fazer e refazer podem ser mais rápido ou mais lento, de modo que uma fotografia, um padrão espacial, pode permanecer por um longo período de tempo ou mudar rapidamente. A dinâmica da segregação, no entanto, é própria do capitalismo, não sendo típica da cidade pré-capitalista, caracterizada por forte imobilismo sócio espacial.

É importante perceber que o espaço urbano é marcado por processos e formas, onde o primeiro geralmente determina o segundo. O processo segregador é dinâmico e apresenta modificações de acordo com o interesse de agentes econômicos, que objetivam moldar o espaço urbano de forma a separar os diferentes grupos que habitam a cidade: os que possuem maior renda habitam os melhores lugares e os de baixa renda habitam os lugares mais precários, quando consideramos a oferta de serviços e equipamentos públicos.

Além da renda, outros fatores contribuem para a segregação de indivíduos no espaço urbano. Podemos destacar os que se fundamentam em convenções éticas e morais. Quando consideramos esta perspectiva, o corpo se apresenta como importante indicador de transgressões cometidas por indivíduos condenados ao isolamento. Certamente, ao estudar a segregação imposta aos hansenianos, percebemos a forte relação estabelecida entre o corpo, o território e as convenções morais. Em Anápolis - GO, o bairro Novo Paraíso foi produzido a partir de determinações convencionadas por uma sociedade que reproduziu o estigma que historicamente acompanha portadores do Bacilo de Hansen. Neste bairro, a segregação e o estigma ainda permeiam o cotidiano dos seus moradores. É o que destacamos a seguir. 
SIQUEIRA, T. A.; MELLO, M.

Segregação e Hanseniase: a produção de uma subnormalidade no município de Anápolis (GO)

\title{
Novo Paraíso: entre a hanseníase e a segregação espacial
}

A hanseníase é uma enfermidade que assombrou a humanidade por séculos. Inúmeros relatos de diferentes épocas descrevem o caminho percorrido por enfermos contaminados por este "mal". Segundo Foucault (1978, p.7), "a partir da alta idade média, e até o final das cruzadas, os leprosários tinham multiplicado por toda a superfície da Europa suas cidades malditas." Os leprosários sempre foram vistos como locais obscuros onde o mal reinava: um mal que deveria ser combatido na perspectiva ditada pela Igreja Medieval. Após a Idade Média, os "leprosos" começaram a desaparecer". Com isto, uma série de iniciativas, vinculadas à retomada da vida urbana, alteraram os usos dos leprosários, que passaram a ser destinados aos cuidados dos indivíduos que colocavam em risco o emergente modo de vida urbano.

Entre a realidade europeia analisada pelo filósofo francês e a realidade anapolina aqui investigada, temos o transcurso de séculos. Contudo, a imagem de degradação física e social do leproso/hanseniano permanece. Maciel (2014, p.15) esclarece que:

\begin{abstract}
A hanseníase é uma doença milenar, associada às condições de pobreza e higiene precárias, que ainda se constitui um relevante problema de saúde no Brasil, onde é considerada de caráter endêmico. O Brasil, atualmente, está em segundo lugar no ranking mundial em número de casos constatados de hanseníase.
\end{abstract}

No caso brasileiro, há um agravante: o descaso dos governantes que não assumem, efetivamente, um compromisso com a erradicação da doença, que está associada diretamente à pobreza e a falta de infraestrutura básica (MACIEL, 2014), o que aproxima ainda mais hanseníase e segregação residencial.

Mesmo sendo uma doença passível de prevenção, a proliferação da hanseníase é classificada como endêmica no Brasil. Além disso, seus portadores continuam sendo atingidos pelos estigmas da lepra. Segundo Maciel (2014, p.17):

O estigma é um componente fundamental no fenômeno social da hanseníase e, provavelmente, também, um importante elo da corrente epidemiológica da doença que não vem recebendo a devida importância por parte das três esferas de governo -

\footnotetext{
5 "É importante mencionar que, segundo a maioria dos estudiosos do assunto, a doença denominada "lepra" permaneceu, até o século XIV, confundida com outras doenças de pele que acometiam a população e não poderiam ser identificados com rigor, assim como a sífilis, o câncer de pele, escarlatina e o lúpus" (MACIEL, 2014, p. 62).
} 
SIQUEIRA, T. A.; MELLO, M.

Segregação e Hanseniase: a produção de uma subnormalidade no município de Anápolis (GO)

municipal estadual e federal - e, tampouco, pelos formuladores de políticas públicas, mesmo sabendo que o seu combate é uma das exigências da OMS (2008; 2010; 2013).

A proliferação da doença e o isolamento dos doentes demonstram a ineficácia do enfrentamento oficial à hanseníase. No passado, o isolamento compulsório era o único tratamento e, na atualidade, o isolamento ainda é uma realidade a ser considerada. Segundo Silva e Salomon (2011, p.4):

\begin{abstract}
A Política médico social, no que concerne à organização de um quadro assistencial e normativo para os problemas da lepra, manifesta-se inserido num projeto de expansão do poder do Estado, com o desenvolvimento de estratégias de disciplinamento social; na prática, enquanto o Estado ainda não se apresentava como mediador da assistência sanitária de sua população leprosa era por meio da atividade caritativa e filantrópica.
\end{abstract}

Nesse sentido, as entidades filantrópicas assumiram um papel fundamental no tratamento da doença, visto que o Estado não oferece assistência adequada aos doentes, agravando ainda mais o processo de segregação. Outra questão importante é a disciplina imposta aos enfermos e seus corpos, o que indica a intenção de normatizar suas vidas. Isso se dá, frequentemente, por meio de condutas morais religiosamente pautadas. Segundo Silva e Salomon (2011, p.1), “no Brasil, a aliança entre política e pedagogia médica pode ser observada no início do século XX, mas é na política nacionalista de Getúlio Vargas após 1930 que ela se fortalece." E é a partir do processo de integração do sertão que nota-se a medicalização da Lepra em Goiás (Silva e Salomon, 2011); contudo, os resultados não foram satisfatórios.

Ao analisar algumas ocorrências manifestadas em Trindade (GO), Silva e Salomon (2011) destacam a intervenção médica e policial empregada na tradicional Romaria, a fim de controlar a presença de doentes e mendigos. "Em 1939, como parte do programa de implantação de políticas sanitárias e esquadrinhamento dos espaços públicos em Goiás, temos a intervenção médica e policial na tradicional Romaria de Trindade" (SILVA; SALOMON, 2011, p.4). Neste caso, as políticas sanitárias contribuíram para o aumento dos estigmas relacionados aos doentes, que eram "caçados" para serem isolados em colônias.

Nesta perspectiva, o que aconteceu na Europa medieval foi reproduzido séculos mais tarde em Goiás: o medo da lepra toma conta da sociedade e medidas segregadoras expulsam os leprosos para fora dos perímetros urbanos. O corpo foi um elemento que 
SIQUEIRA, T. A.; MELLO, M.

Segregação e Hanseniase: a produção de uma subnormalidade no município de Anápolis (GO)

justificou a segregação. Os indivíduos que apresentavam - em seus corpos - sinais da doença eram, imediata e sumariamente, condenados por desvios morais e, por esta razão, deviam pagar um alto preço por desobedecer aos desígnios Divinos estabelecidos pela Igreja. Desta forma, muitos familiares se viram obrigados a habitar lugares que margeavam os leprosários. Lugares marcados pela ausência de serviços e equipamentos básicos.

O bairro Novo Paraíso, em Anápolis (GO), foi produzido no contexto apresentado no parágrafo anterior, quando migrantes com hanseníase chegaram ao município em análise e foram segregados para fora de seu perímetro urbano. Como marca deste processo, ainda hoje o estigma da "lepra" se faz presente na vida de seus moradores. Além da questão da doença, os moradores do bairro enfrentam problemas vinculados à falta de infraestrutura básica e ausência de serviços públicos. A população do bairro encontra-se na condição de herdeira do isolamento que caracterizou sua origem.

Segundo Tavares; Peixoto; Luz; Campos; Monteiro (2015), o crescimento econômico da década de 1930 atraiu um expressivo contingente populacional para Anápolis (GO), constituído por pessoas saudáveis e pessoas doentes. No grupo de doentes, a hanseníase ocupou lugar de destaque. Historicamente, o bairro Novo Paraíso, Figura 1, tem sua origem nas demandas por segregação de portadores da hanseníase. Naquele momento, esta era uma prática comum e reproduzia uma tendência geral.

A Figura 1 representa a localização do bairro Novo Paraíso. O bairro está localizado na periferia da cidade, o que nos permite ter uma ideia do isolamento experimentado pelos primeiros moradores, nas décadas de 1930 e 1940. Na década de 1930, Anápolis passou por mudanças significativas, inclusive no seu espaço urbano, com a chegada da ferrovia. As expectativas progressistas atraíram pessoas de diversas partes do país e os "leprosos" estavam presentes na cidade. Em Anápolis era comum ver "leprosos" perambulando furtivamente pelas ruas; bem como nas festividades religiosas (TAVARES; PEIXOTO; LUZ; CAMPOS; MONTEIRO, 2015). Este cenário promovia o medo da contaminação e reforçava o preconceito dirigido aos hansenianos. 
SIQUEIRA, T. A.; MELLO, M.

Segregação e Hanseniase: a produção de uma subnormalidade no município de Anápolis (GO)

Figura 1: Mapa de Localização do bairro Novo Paraiso em Anápolis - GO (2018)

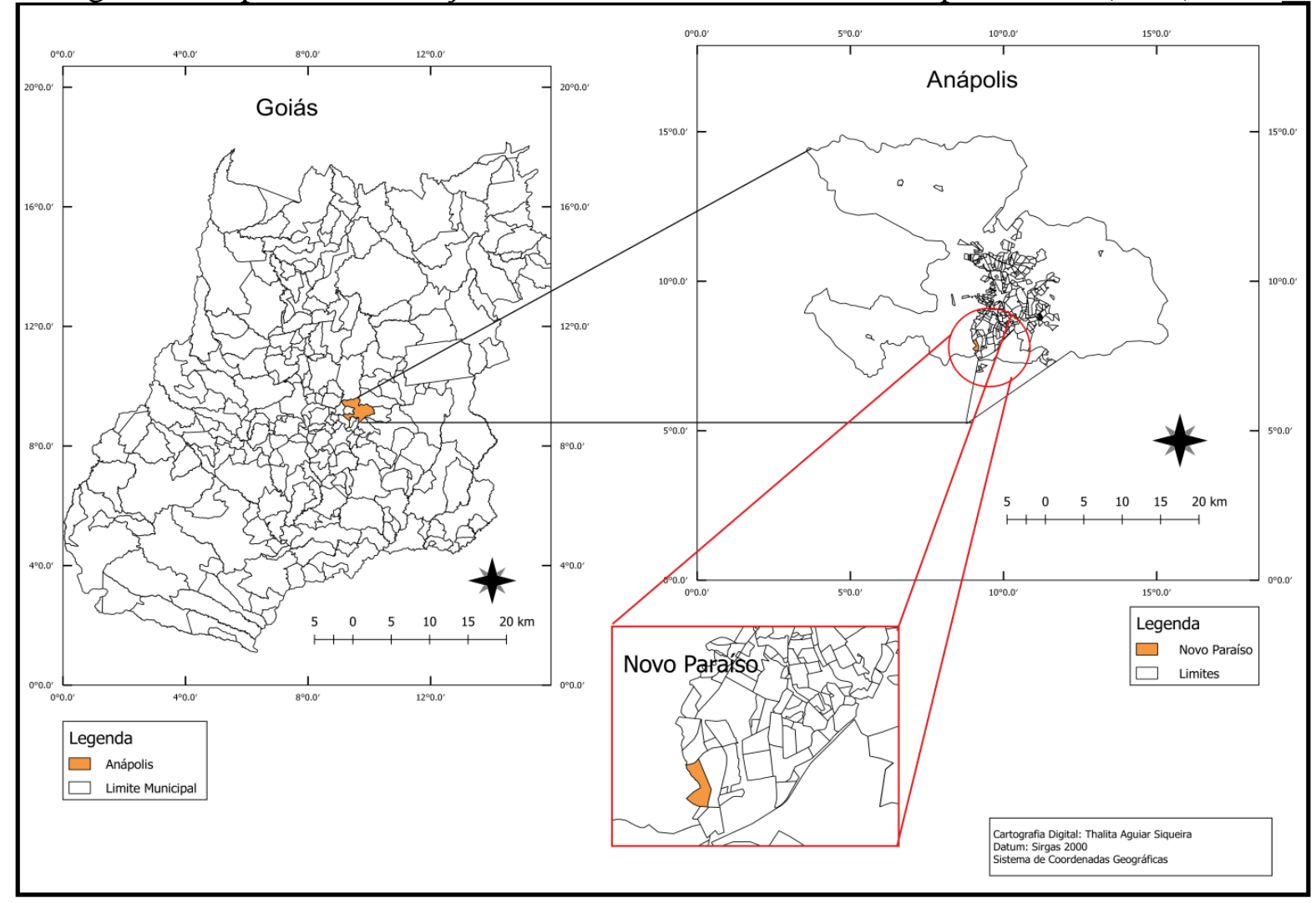

Fonte: Siqueira, T. A, 2018.

E foi justamente no período aqui destacado que Getúlio Vargas, preocupado em viabilizar o processo industrializador-urbanizador no Brasil, estabeleceu a centralização das ações de isolamento. Estas ações foram estendidas por todo o país. Em 1930, a Sociedade São Vicente de Paulo construiu um leprosário em Anápolis, em um momento em que o isolamento compulsório era a principal iniciativa assumida pelos agentes públicos e privados (TAVARES; PEIXOTO; LUZ; CAMPOS; MONTEIRO, 2015).

Dez anos depois, com a criação da Colônia Santa Marta ${ }^{6}$, Figura 2, em Goiânia, a instituição anapolina foi desativada. Em relação à Colônia Santa Marta, Tavares; Peixoto; Luz; Campos; Monteiro (2015, p.116) relatam:

O território da lepra tem, nesse momento, novo endereço, isolado, localizado $8 \mathrm{~km}$ da nova capital e de difícil acesso. O território era uma cidade-hospital, posto que lá havia moradia, trabalho, lazer, cemitério, cadeia, etc., bem como $70 \mathrm{~km} 2$ de terra para cultivo agrícola, atividade utilizada como terapia por meio do trabalho. Ela

\footnotetext{
${ }^{6}$ A colônia Santa Marta foi transformada em 1983 em Hospital Estadual de Dermatologia Sanitária e Reabilitação Santa Marta, em consequência da nova política de atenção às pessoas com hanseníase e de diretrizes nacionais de desospitalização para estes pacientes.
}

Revista Cerrados, Montes Claros/MG, v.17, n. 2, p. 25-46, jul./dez.-2019. 
SIQUEIRA, T. A.; MELLO, M.

Segregação e Hanseniase: a produção de uma subnormalidade no município de Anápolis (GO)

possuía estrutura arquitetônica dividida em zonas: sadia; doente e observação. Este modelo privilegiava o risco zero. Apesar da estrutura de isolamento que havia na Colônia ainda se registrava fuga de considerável número de doentes.

A Colônia Santa Marta era a materialização da segregação. O lugar de isolamento dos doentes não oferecia o mínimo de dignidade. A instituição de internação isolava os hansenianos, que não tinham contato com seus familiares. Segundo (SILVA, 2013, p. 243):

A Colônia Santa Marta, desde a sua inauguração em 1943, encerrava em sua área de 25 hectares uma considerável população que se assemelhava por uma condição, sui generis, seu estado de saúde. Após a constatação da doença, esses indivíduos eram compulsoriamente arrancados do seio de suas famílias e fechados dentro do hospital-colônia, subordinavam-se a novas regras de subsistência.

A figura 2 representa a localização da Colônia Santa Marta em relação à cidade de Goiânia. A distância da instituição do espaço urbano da nova capital goiana torna perceptível à lógica do isolamento. A situação na Colônia era tão desfavorável que muitos doentes fugiram, inclusive para o bairro Novo Paraíso, em Anápolis. Na atualidade, depois de transcorridas décadas, o bairro anapolino permaneceu isolado da cidade. Nem mesmo um expressivo processo de crescimento urbano horizontal aproximou o bairro das demais áreas urbanizadas, ver Figura 1.

Figura 2: Localização da Colônia Santa Marta

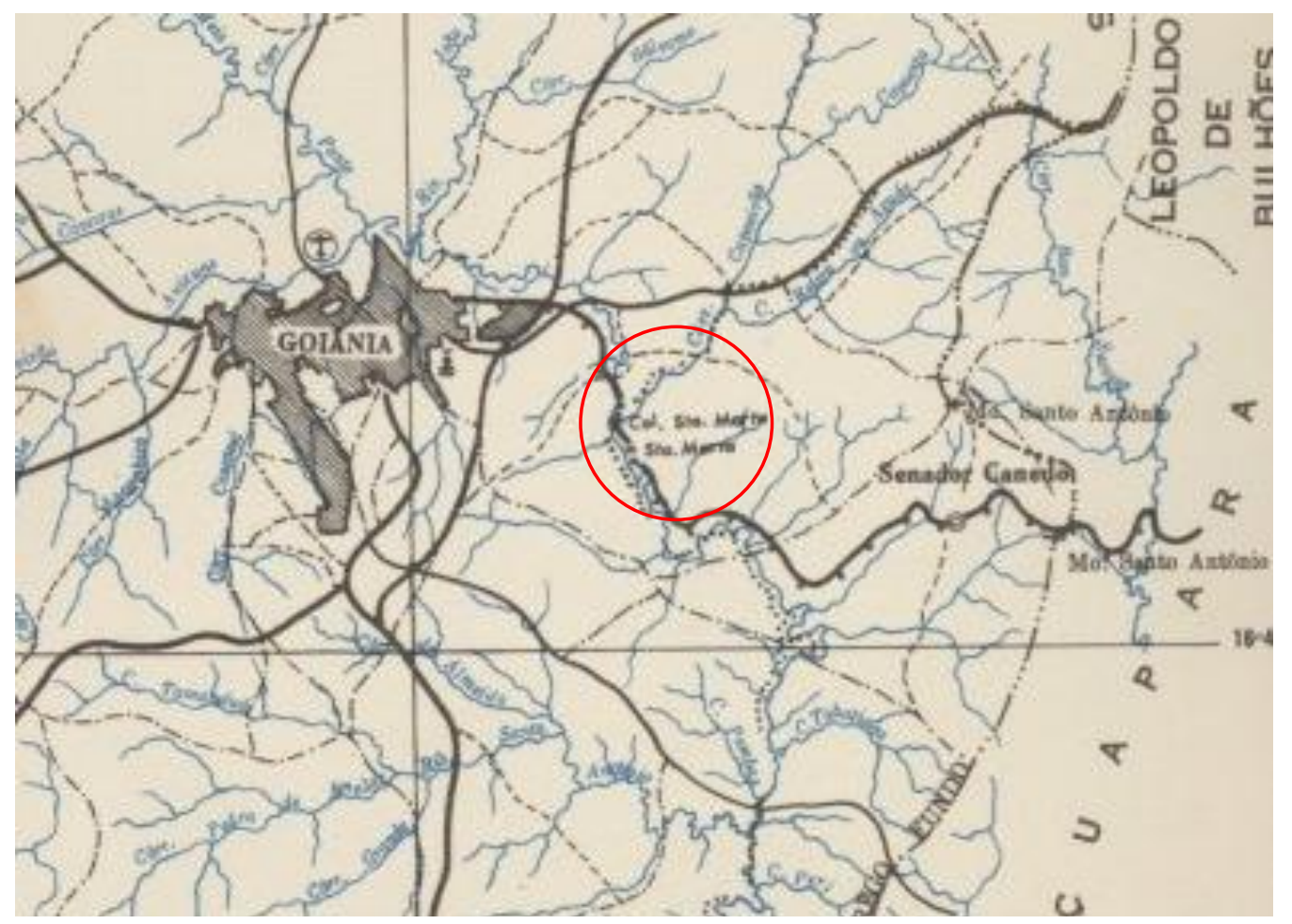

Fonte: Instituto Brasileiro de Geografia e Estatísticas (IBGE) - 1957

Revista Cerrados, Montes Claros/MG, v.17, n. 2, p. 25-46, jul./dez.-2019. 
SIQUEIRA, T. A.; MELLO, M.

Segregação e Hanseniase: a produção de uma subnormalidade no município de Anápolis (GO)

É importante ressaltar que passados dez anos da construção da Colônia Santa Marta, o bairro Novo Paraíso tornou-se o refúgio para doentes e familiares que fugiram de Colônias de internação do país inteiro (Quadro 1). Segundo Tavares; Peixoto; Luz; Campos; Monteiro (2015, p.111): "Eles vinham de várias partes do país, fugindo, em sua maioria, de Colônias. Estava formado o "refúgio dos leprosos", no qual as regras eram ditadas ora pelos doentes, ora por grupos religiosos que se apropriavam do território para controle local”.

Quadro 1: Colônias Fundadas no Brasil até a Década de 1930

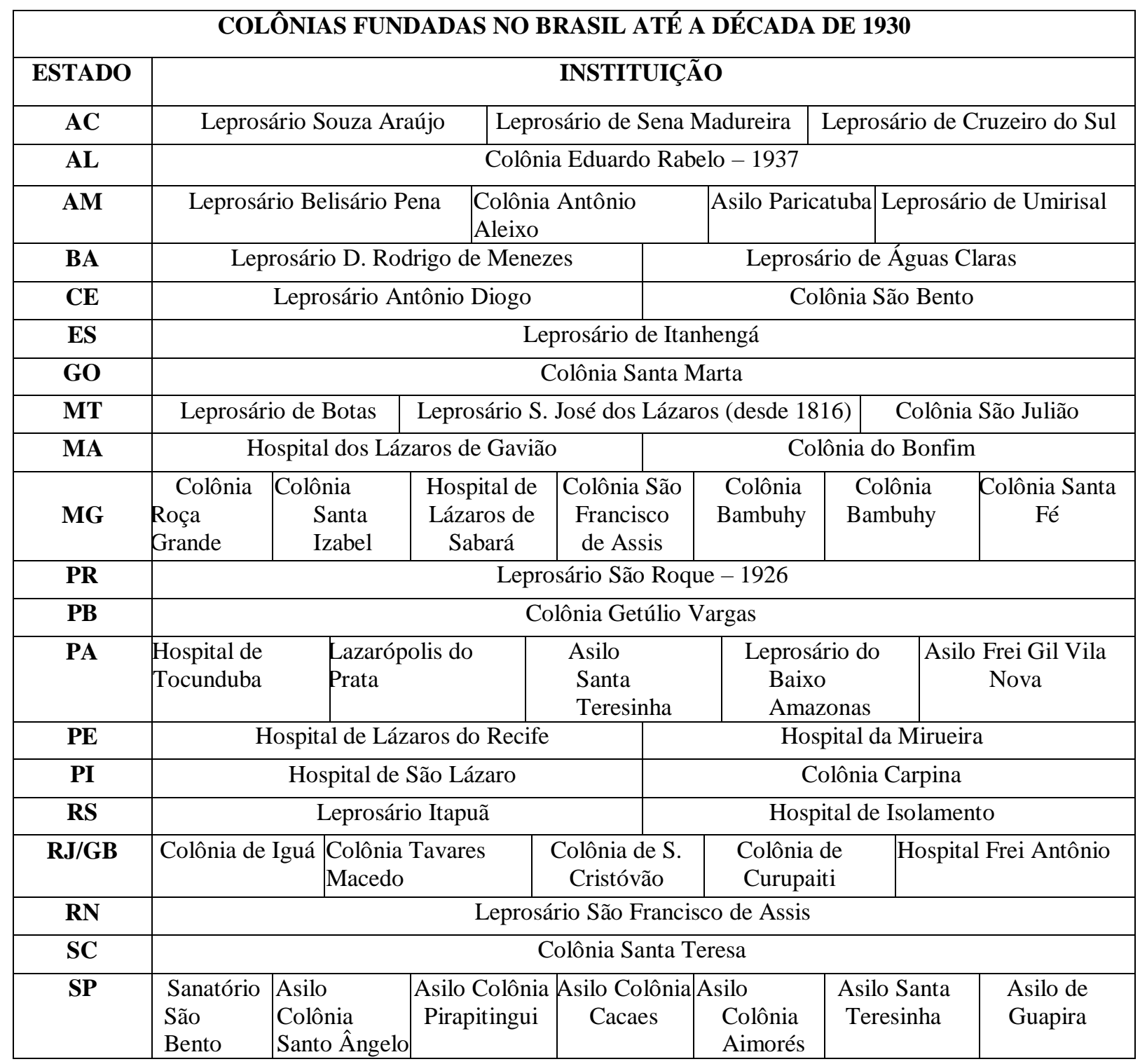

Fonte: MACIEL, R. M. T, 2014.

Revista Cerrados, Montes Claros/MG, v.17, n. 2, p. 25-46, jul./dez.-2019. 
SIQUEIRA, T. A.; MELLO, M.

Segregação e Hanseniase: a produção de uma subnormalidade no município de Anápolis (GO)

Os doentes e seus familiares ocuparam o território ao lado do antigo leprosário. Segundo Tavares; Peixoto; Luz; Campos; Monteiro (2015, p.118) “as décadas de 1950, 1960 e 1970 marcam a criação, implantação e consolidação do território usado para o refúgio. " Tavares; Peixoto; Luz; Campos; Monteiro (2015) relatam que moradores foram "caçados" a partir da implementação de políticas sanitárias: imperava o medo do retorno ao lugar de isolamento. A partir de então, o bairro de Novo Paraíso foi crescendo e se consolidando como aglomerado subnormal. Uma marca evidente da segregação residencial, Segundo (TAVARES; PEIXOTO; LUZ; CAMPOS; MONTEIRO, 2015, p.110):

grupos em situação de miséria residentes em Anápolis se agregaram aos leprosos e constituíram um território doente e miserável, abandonado pelo poder público, ficando a mercê dos cuidados de grupos que muitas vezes eram responsáveis por conflitos existentes no local.

Os "leprosos" estabeleceram uma relação particular com o território. No que se refere à história de Novo Paraíso, a partir da afirmação do doente como indivíduo que tem o direito de viver em sociedade, cria-se uma alternativa ao isolamento territorial e social.

Em Anápolis, a hanseníase está vinculada ao processo de segregação sócioespacial. Como mediador histórico deste processo, temos setores da Igreja Católica, que colaboraram no processo de produção de um espaço em que o "leproso" não fosse condenado ao isolamento absoluto. Contudo, o Estado não acompanhou a ação da Igreja, o que redundou na inexistência de serviços e equipamentos públicos necessários ao enfrentamento da enfermidade, perpetuando o cenário de isolamento.

Outra entidade importante nesse contexto é o $\mathrm{MOHAN}^{7}-$ Movimento de Reintegração das pessoas Atingidas pela Hanseníase. O MOHAN é uma entidade Nacional sem fins lucrativos, com atividades voltadas para a erradicação da hanseníase. Um de seus núcleos está situado no bairro Novo Paraíso. Ainda hoje, apesar de a doença estar controlada, o bairro Novo Paraiso sofre com os reflexos do estigma, do preconceito e da segregação. As condições em que os moradores do bairro vivem representam a perpetuação de um processo continuado, fazendo com que a pobreza, a precariedade das moradias, a violência e a degradação ambiental sejam constantes na vida de seus habitantes.

\footnotetext{
7 “O MORHAN surgiu no contexto de grande agitação e movimentos sociais que caracterizam o início da década de 1980 no Brasil. A origem do movimento está nas discussões de enfoque político sobre a hanseníase, realizadas por um grupo de pessoas na década de 1970. Sua criação data de junho de 1981, e logo em seguida deu-se a recomendação oficial para o fechamento das colônias e preventórios e a introdução de medidas de saúde pública para controle da hanseníase" (MACIEL, 2014, P. 114)

Revista Cerrados, Montes Claros/MG, v.17, n. 2, p. 25-46, jul./dez.-2019.
} 
SIQUEIRA, T. A.; MELLO, M.

Segregação e Hanseniase: a produção de uma subnormalidade no município de Anápolis (GO)

\section{Os dados da segregação residencial no Novo Paraíso}

Para identificar aspectos socioeconômicos relacionados ao processo segregador manifestado no bairro Novo Paraíso, foram realizados trabalhos de campo e aplicados 50 questionários. Os questionários foram aplicados intercalando as casas das quadras do bairro, abrangendo todo o seu território.

Cada questionário apresenta 22 questões, com informações referentes à identificação da realidade familiar dos respondentes e a avaliação da qualidade da infraestrutura do bairro, a partir da percepção dos moradores. Os dados analisados corroboram com a classificação de subnormalidade atribuída pelo IBGE (2010).

No presente artigo, optamos por conjugar três variáveis socioeconômicas que permitem visualizar a realidade vivida pela população a partir da renda; com o intuito de verificar a existência de um estado de vulnerabilidade social. As variáveis destacadas foram: número de moradores por domicílio; quantidade de pessoas por domicilio que contribuem com a renda familiar e renda familiar mensal. Em relação ao número de pessoas por domicílio, nos deparamos com a realidade indicada no Gráfico 1:

Gráfico 1 - Número De Residentes Por Domicilio - 2016

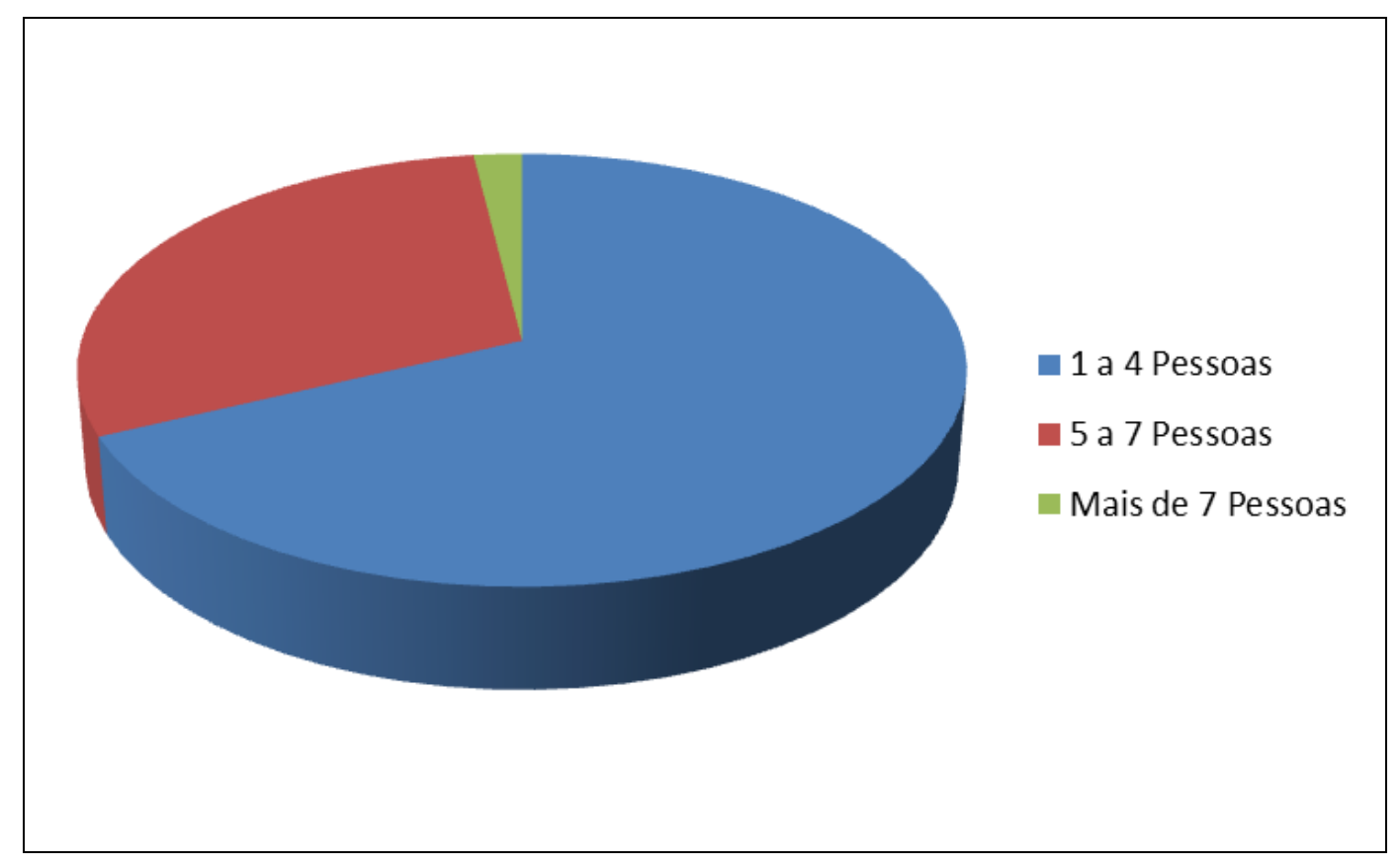

Fonte: Elaboração da Autora

Revista Cerrados, Montes Claros/MG, v.17, n. 2, p. 25-46, jul./dez.-2019. 
SIQUEIRA, T. A.; MELLO, M.

Segregação e Hanseniase: a produção de uma subnormalidade no município de Anápolis (GO)

De acordo com o Gráfico 1, 68\% dos domicílios visitados possuem entre 1 e 4 residentes; $30 \%$ têm entre 5 e 7 e $2 \%$ mais de 7 residentes. A aplicação do questionário permitiu a análise da estrutura das casas, que se revelaram incompatíveis com as demandas básicas das famílias, pois, em sua maioria, não têm banheiros e quartos em quantidade suficiente. No tocante ao quantitativo de habitantes por domicilio que contribuem com a renda familiar, destacamos o Gráfico 2.

Gráfico 2: Número De Pessoas Que Contribuem Com A Renda Do Domicilio - 2016

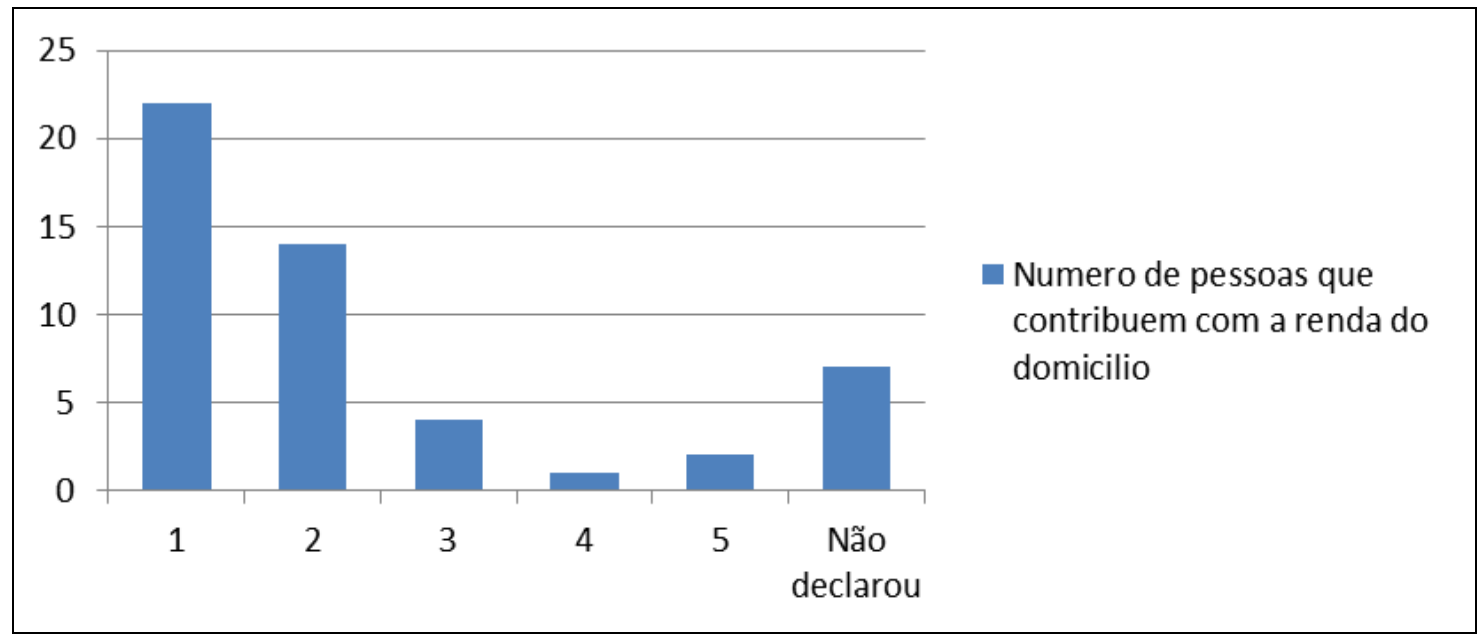

Fonte: Elaboração da Autora

Ao analisar o número de pessoas que contribuem com a renda do domicílio, verificamos que em $44 \%$ dos domicílios visitados apenas uma pessoa contribui com a renda; em $28 \%$ duas pessoas contribuem; em $8 \%$ três pessoas contribuem; em 2\% dos domicílios quatro pessoas contribuem; em $4 \%$ domicílios cinco pessoas contribuem com a renda e em $14 \%$ dos domicílios os entrevistados não quiseram ou souberam responder.

A realidade apresentada redunda em um universo marcado por uma baixa renda familiar mensal, pois além do baixo número de pessoas que contribuem com a renda - em quase $50 \%$ dos domicílios somente um residente contribui na obtenção da renda -, os rendimentos recebidos individualmente são baixos (Gráfico 3). 
SIQUEIRA, T. A.; MELLO, M.

Segregação e Hanseniase: a produção de uma subnormalidade no município de Anápolis (GO)

Gráfico 3: Rendimento Familiar Mensal - 2016

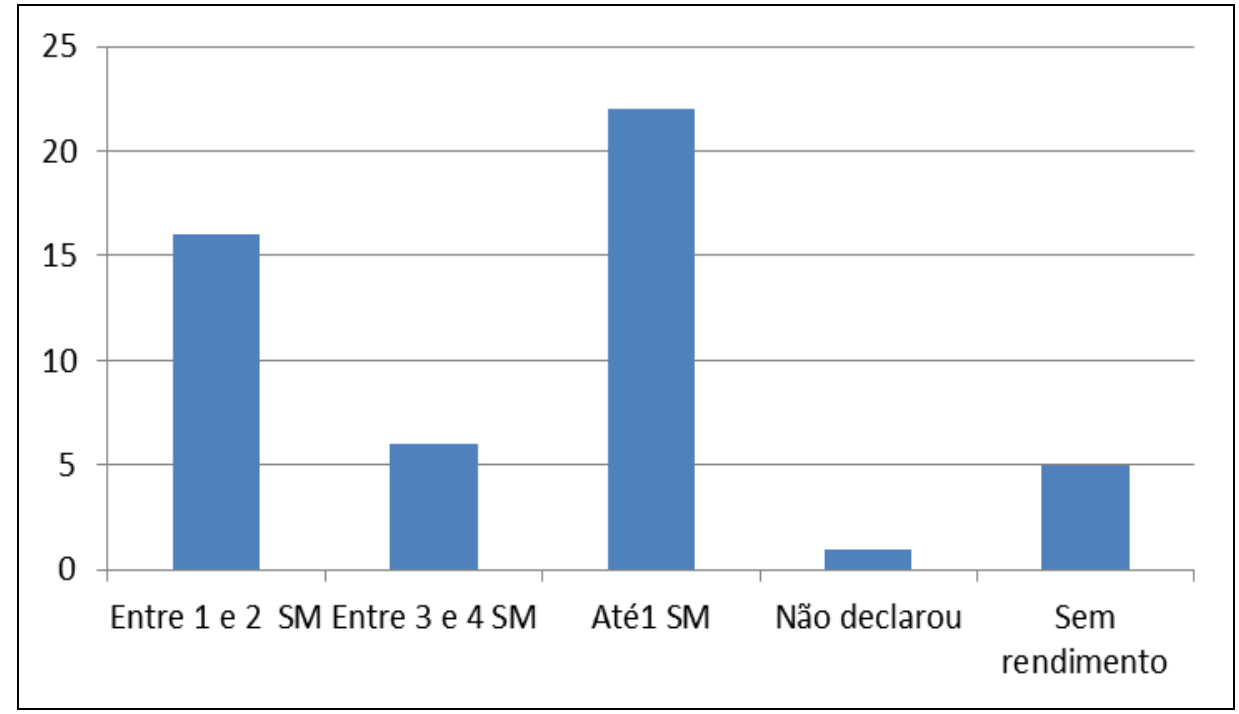

Fonte: Elaboração da Autora

Os dados analisados revelam que $10 \%$ dos domicílios não possuem rendimento, como em $14 \%$ dos domicílios os entrevistados não informaram quantas pessoas contribuem com a renda mensal, entendemos que há uma articulação entre os dados colhidos, indicando que os $10 \%$ sem rendimentos estão contidos no universo de $14 \%$ que não informaram o quantitativo de residentes que contribuem com a renda; dando sequência à análise da renda familiar mensal, em 44\% dos domicílios o rendimento é de até um salário mínimo; em 32\% o rendimento está situado entre 1 e 2 salários mínimos; em 12\% o rendimento é de 3 a 4 salários mínimos e em $2 \%$ dos domicílios os entrevistados não declararam seu rendimento mensal.

O cenário delineado pela pesquisa revela que $54 \%$ dos domicílios estão situados entre a ausência de renda e a renda menor de um salário mínimo mensal, o que indica uma situação de continuidade de um processo produtor de um estado de vulnerabilidade social. A limitação do acesso à educação, a saúde e ao transporte público ${ }^{8}$, somado a baixa renda, explica a dificuldade de superação da precariedade nas condições de vidas dos moradores de Novo Paraíso: condições reproduzidas historicamente, em um território pensado para segregar hansenianos e seus familiares na primeira metade do século XX.

\footnotetext{
${ }^{8} \mathrm{Na}$ pesquisa realizada foi detectado que $8 \%$ dos respondentes nunca frequentaram a escola; $50 \%$ possuem o ensino fundamental incompleto; $10 \%$ o ensino fundamental completo e $32 \%$ o ensino médio completo. Quanto ao transporte público, não existem linhas de transporte coletivo que atentam o bairro. Os usuários têm que andar longas distâncias para pegar um ônibus.

Revista Cerrados, Montes Claros/MG, v.17, n. 2, p. 25-46, jul./dez.-2019.
} 
SIQUEIRA, T. A.; MELLO, M.

Segregação e Hanseniase: a produção de uma subnormalidade no município de Anápolis (GO)

\section{CONSIDERAÇÕES FINAIS}

O espaço urbano é, notadamente, marcado por complexidades, o que solicita investigações científicas sobre os mais variados temas. A segregação é um tema recorrente nos estudos centrados no espaço urbano e, ainda assim, gera indagações passiveis de discussões, tanto no âmbito acadêmico como em outras esferas que regem a vida em sociedade.

Ao longo da pesquisa, consideramos que a segregação deve ser percebida como um processo histórico. Essa condição demanda, no âmbito da ciência, uma evolução conceitual. $\mathrm{O}$ amadurecimento de um conceito se apresenta como fundamental, pois à medida que a sociedade se transforma e se complexifica, temos a necessidade de bases teóricas e conceituais mais sólidas. Nesta perspectiva, o conceito de segregação residencial passou pelo crivo de diversos cientistas, em diversas épocas; enfatizando a sua importância e enriquecendo as análises realizadas a partir dele.

Ao apresentar a realidade do bairro Novo Paraíso, destacamos que a segregação residencial está ligada a diversos fatores, como a saúde, que, nesse caso, apresenta-se como elemento segregador. No curso da investigação, analisamos o caminho percorrido pelo conceito de segregação, a fim de criar bases para compreensão da realidade encontrada no bairro Novo Paraíso.

A área onde se encontra o bairro Novo Paraíso é uma área de vulnerabilidade ambiental, as casas são precárias e a falta de infraestrutura básica é evidente. A renda das famílias é baixa, pois o subemprego é a única forma de garantir seu sustento. A violência é constante e o isolamento enfrentado pelas famílias evidencia a gravidade do processo segregador reproduzido em um bairro produzido para isolar hansenianos.

\section{AGRADECIMENTOS}

A Universidade Estadual de Goiás, por oferecer um ambiente favorável ao desenvolvimento da pesquisa, e a CAPES, pela bolsa de mestrado concedida.

\section{REFERÊNCIAS}

CARLOS, A.F.A. O espaço urbano: novos escritos sobre a cidade: São Paulo: Labur Edições, 2007. Disponível em:<http://www.fflch.usp.br/dg/gesp> Acesso em: 12/04/2016. 
SIQUEIRA, T. A.; MELLO, M.

Segregação e Hanseniase: a produção de uma subnormalidade no município de Anápolis (GO)

CLARK, D. Introdução à Geografia Urbana. São Paulo: DIFEL Difusão editorial S.A, 1985.

CORRÊA, R. L. O Espaço Urbano. São Paulo: Ática, 1995.

FOUCAULT, M. História da loucura na idade clássica. São Paulo: PERSPECTIVA, 1978.

IBGE. Instituto Brasileiro de Geografia e Estatística. Aglomerados Subnormais:

Informações Territoriais Censo 2010. Disponível em < http://www.ibge.gov.br/home/presidencia/noticias/imprensa/ppts/00000015164811202013480 105748802.pdf > Acesso em: 24/08/2016.

LEFEVRE, Henri. O Direito à Cidade. São Paulo: Centauro, 2001. Disponível em:<http://www.professorreinaldosousa.com/livros/> Acesso em: 10/03/2016.

LOJKINE, J. O estado capitalista e a questão urbana. São Paulo: Martins Fontes, 1997.

MACIEL, R. M. T. De leprosários e preventórios à hanseníase tem cura: saldos de um passado que insiste em existir 2014. Tese (doutorado) - Universidade Federal do Rio de Janeiro, Instituto de Economia, Programa de Pós-Graduação em Políticas Públicas, Estratégias e Desenvolvimento, Rio de Janeiro ,2014.

MOHAN. Disponível em: <http://www.morhan.org.br/>. Acesso em: 10/12/2016

PEREIRA, A. D. A (longa) história da desigualdade na África do Sul. Mal-estar na cultura. Abril-Novembro, 2010. Disponível em: <

http://www.ufrgs.br/difusaocultural/adminmalestar/documentos/arquivo/AfricaDoSulDanilevi czPereira.pdf> Acesso em: 20/11/2016.

ROUSSEAU, J.J. Discurso sobre a origem e os fundamentos da desigualdade entre os homens. In: Os pensadores. São Paulo: Abril Cultural, 1978.

SILVA, L.F. Eternos Órfãos Da Saúde: Medicina, Política E Construção Da Lepra Em Goiás (1830-1962). Tese de doutorado apresentada ao Programa de Pós-Graduação em História da Universidade Federal de Goiás (UFG), Goiânia, 2013.

SILVA, L. F; SALOMON, M. J. A lepra em Goiás (1920-1937): as instituições filantrópicas e a pedagogia do isolamento. In: VIII Congresso de Pesquisa, Ensino e Extensão - Conpeex, Goiânia. 2011. Disponível em: <

http://www.sbpcnet.org.br/livro/63ra/conpeex/doutorado/trabalhosdoutorado/doutorado-leicyfrancisca.pdf> Acesso em: 05/08/2016.

SOUZA, M.L. ABC do desenvolvimento urbano. Rio de Janeiro: Bertrand Brasil, 2010.

TAVARES, G.G; PEXOTO, J.C; LUZ, J.S; CAMPOS, D.M.B; MONTEIRO, R.S. A Lepra Mora no Morro: O “refúgio" de leprosos em Anápolis, Goiás, Brasil (1930 -1970). 
SIQUEIRA, T. A.; MELLO, M.

Segregação e Hanseniase: a produção de uma subnormalidade no município de Anápolis (GO)

Fronteiras: Journal of Social, Technologicaland Environmental Science. v.4, n.1, jan. -jul. 2015. Disponível em: <http://revistas.unievangelica.edu.br/index.php/fronteiras/ > Acesso em: 10/08/2016.

VASCONCELOS, P.A; CORREAA, R.L; PINTAUDI, S.M (Orgs). A cidade contemporânea: segregação espacial. São Paulo: contexto. 2013.

VASCONCELOS, P.A. A aplicação do conceito de segregação residencial ao contexto brasileiro na longa duração. CIDADES. São Paulo v. 1, n. 2, 2004, p. 259-274. Disponível em:<http://revista.fct.unesp.br/index.php/revistacidades/article/viewFile/478/508> Acesso em: $29 / 03 / 2016$

VILLAÇA, F. Espaço Intra-urbano no Brasil. São Paulo: Studio Nobel, 2001.

\section{Autores}

Thalita Aguiar Siqueira - Possui Graduação em Geografia pela Universidade Estadual de Goiás (UEG). Atualmente é Acadêmica do Programa de PósGraduação em Territórios e Expressões Culturais no Cerrado (TECCER) da Universidade Estadual de Goiás (UEG).

Marcelo de Mello - Possui Graduação, Mestrado e Doutorado em Graduação em Geografia pela Universidade Federal de Goiás (UFG). Atualmente é professor do Programa de PósGraduação em Territórios e Expressões Culturais no Cerrado (TECCER) da Universidade Estadual de Goiás (UEG).

Artigo recebido em: 05 de junho de 2019.

Artigo aceito em: 11 de julho de 2019.

Artigo publicado em: 17 de julho de 2019. 